\title{
EVOLUÇÃO E MAPEAMENTO DO USO DA TERRA, ATRAVÉS DE IMAGENS AEROFOTOGRAMÉTRICAS E ORBITAIS EM SANTA BÁRBARA D'OESTE (SP)
}

\author{
M.H. BORGES \\ Departamento de Cartografia - FCT/UNESP, C.P. 957 - CEP: 19060-900 - Presidente Prudente,SP. \\ R.M. PFEIFER \\ Instituto Florestal de São Paulo, C.P. 1322 - CEP: 01000-970 - São Paulo,SP. \\ J.A.M. DEMATTE \\ Departamento de Ciência do Solo-ESALQ/USP, C.P. 9, CEP: 13418-900 - Piracicaba,SP
}

\begin{abstract}
RFSUMO: Em Santa Bárbara D'Oeste,SP, foram realizados dois mapeamentos do uso da terra em área de 14.625 ha. No primeiro utilizou-se fotografias aéreas verticais pancromáticas (data de 25/6/78), na escala 1:35.000, e no segundo utilizou-se imagens orbitais do satelite LANDSAT-5 com sensor "Thematic Mapper" (data de 12/8/91), escala 1: 100.000, nas bandas 3, 4 e 5 e composição colorida 3/4/5. Para auxiliar a confecção desses mapas, obteve-se chaves de interpretação, tanto para as aerofotos como para as imagens orbitais. As fotografias aéreas proporcionaram um maior nível de detalhamento na identificação do uso da terra. A banda 3 e a composição colorida 3/4/5 foram as mais eficientes entre as imagens orbitais. Entre 1978 e 1991, a área de ocorrência de cana-deaçúcar permaneceu a mesma, as áreas de mata e pastagem diminúram, enquanto que as áreas de refiorestamento e urbana aumentaram. Essa região teve sua capacidade de uso enquadrada, na maior parte, na classe IV: terras mais apropriadas para pastagens ou plantas perenes como a cana-de-açúcar, devendo-se aplicar técnicas intensivas de conservação, e com aptidão baseada em práticas agricolas que refletem um alto nível tecnologico.

Descritores: mapeamento, uso da terra, fotografia aérea, imagens orbitais
\end{abstract}

\section{LAND USE MAPPING AND EVOLUTION THROUGH AERIAL PHOTOGRAPIS AND ORBITAL IMAGES, IN SANTA BÁRBARA D'OESTE (SP)}

\begin{abstract}
Land use was studied in Santa Barbara D'Oeste,SP in an area of 14,625 ha. Two land use mappings were made using pancromatic aerial photographs (date 25/6/78), in a scale of 1:35,000 and orbital images from LANDSAT-5 satellite (date 12/8/91) in a scale 1:100,000, at bands 3,4 and 5 and color composition 3/4/5. Interpretation keys for aerial photos and orbital images were established to assist map making. For land use identification photos presented more details. On the other hand, orbital images at band 3 and color composition $3 / 4 / 5$ were more efficient in relation to the other bands. Sugar cane crop area did not change in the studied period (19781991), forest and pasture areas had a reduction and urban areas increased. Using the land capability classification, most of the studied area fell in class IV: land more appropriate for pasture or perennial crops like sugar cane, with the need of intensive conservation managements technics, with agricultural practices based on high technological levels.
\end{abstract}

Key words: land use mapping, aerial photos, orbital images

\section{INTRODUÇÃO}

As primeiras classificações de uso da terra baseavam-se em trabalhos de campo. Posteriormente, a partir de década de 50, um grande número de pesquisadores em várias parte do mundo têm se dedicado à identificação detalhada de culturas agrícolas em fotografias aéreas (STEINER, 1970).

Com o advento das imagens orbitais na década de 70, o mapeamento do uso e ocupação do solo em uma dada região ganhava mais um importante instrumento como auxílio.

Esse tipo de trabalho tornou-se de fundamental importância para a compreensão dos padrões de organização do espaço agrícola, cada vez mais alterado pela ação do homem e pelo desenvolvimento tecnológico. Deste modo, existe a necessidade de atualização constante dos registros de uso e ocupação do solo, para que suas tendências possam ser analisadas, com o objetivo de fornecer subsídios às ações do planejamento regional (ROSA, 1990). Ainda segundo este autor, o conhecimento atualizado das formas de utilização e ocupação do solo, bem como seu uso histórico, tem sido um fator imprescindível ao estudo dos processos que se desenvolvem na região, tornandose de fundamental importância, na medida em que os efeitos do seu mau uso, causam deterioração no 
meio ambiente. Os processos de erosão intensos, desertificação, inundações, assoreamentos de cursos d'água têm sido exemplos cotidianos de mau uso.

Face a isso, este trabalho teve por objetivos a obtenção de 2 mapas de uso do solo, sendo o $1^{\circ}$ de 1978, utilizando fotografias aéreas verticais pancromáticas na escala aproximada de 1: 35.000 , e $02^{\circ}$ do uso em 1991, obtido pela utilização de imagens orbitais TM/LANDSAT- 5 nas bandas 3,4 e 5 e composição colorida 3B/4G/5R, na escala 1 : 100.000. A partir desses mapas, póde-se quantificar e estudar a evolução do uso no período entre 1978 e 1991.

Pretendeu-se também, caracterizar os padrões das imagens, das comunidades presentes, a fim de aprimorar o emprego da análise visual de produtos de sensoriamento remoto, no estudo cartográfico do uso atual da região de Santa Bárbara D'Oeste. Além deste aspecto convém enfatizar o fato de que esta região está sendo alterada muito rapidamente devido a pressão urbana.

\section{MATERIAL E MÉTODOS}

\section{Características gerais da área de estudo}

A área de estudo situa-se entre os paralelos $22^{\circ} 43^{\prime}$ e $22^{\circ} 50^{\prime}$ de latitude Sul e os meridianos $47^{\circ} 20^{\prime}$ e $47^{\circ} 28^{\prime}$ de longitude W.Gr., com uma área aproximada de 14.625 ha (Figura 1). A geologia, segundo o Instituto de Pesquisas Tecnológicas - IPT (1981), está representada por rochas intrusivas básicas tabulares, da formação Serra Geral,arenitos e folhelhos de granulação variada do grupo Tubarão e por coberturas Cenozóicas indiferenciadas correlatas à formação Rio Claro (arenitos finos a médios, argilosos com níveis subordinados de argilitos $e$ arenitos conglomeráticos).

O clima da área segundo o sistema de Köeppen é do tipo Cwa, ou seja, mesotérmico de inverno seco em que a temperatura média do mês mais frio $\operatorname{c}$ inferior à $18^{\circ} \mathrm{C}$ e no mês mais quente ultrapassa a $22^{\circ} \mathrm{C}$. $O$ índice pluviométrico deste tipo climático varia entre 1.100 e $1.700 \mathrm{~mm}$ e a temperatura do mês mais quente oscila entre $22 \mathrm{e}$ $24^{\circ} \mathrm{C}$. Para a área de estudo a vegetação original é do tipo floresta latifoliada tropical semidecídua. Esta formação vegetal $\varepsilon$ menos densa e menos exuberante que a floresta latifoliada tropical, refletindo as condições dos solos que as suportam (COMISSÃO DE SOLOS, 1960).
Em relação aos solos, OLIVEIRA et al. (1977) elaboraram o levantamento pedológico semidetalhado da Quadricula de Campinas, na escala 1: 100.000, na qual está inserida a área de estudo. Foram identificadas 13 unidades taxonômicas, sendo as principais: Latossolo Roxo distrófico, Latossolo Vermelho-Escuro, Podzólico VermelhoAmarelo, Terra Roxa Estruturada e Litossolos.

Pelo Atlas de Zoneamento Agrícola do estado de São Paulo (SÃO PAULO, 1974), a área foi mapeada com as classes I-II-III, III-IV e IV de capacidade de uso das terras (CHIARINI; DONZELLI, 1973) e de acordo com o MINISTÉRIO DA AGRICULTURA (1979), a área de estudo foi mapeada segundo a aptidão agrícola das terras como 1 aBC e 1" aBC (aptidão boa para lavouras, em pelo menos um dos níveis de manejo A, B ou C).

\section{Material fotográfico}

Foram empregadas fotografias aéreas, que se apresentam na forma de cópias de papel, em preto-e-branco, na escala aproximada de 1: 35.000 , no formato $230 \mathrm{~mm} \times 230 \mathrm{~mm}$, vôo realizado pela TERRAFOTO S/A em 25/6/78.

Os produtos fotográficos do sensor "Thematic Mapper" do LANDSAT-5, estão sob a forma de cópias em papel, em preto-e-branco em três diferentes bandas: TM-3 $(630-690 \mathrm{~nm})$, correspondente a região do vermelho, TM-4 (760 $900 \mathrm{~nm}$ ), correspondente ao infravermelho próximo, TM-5 (1.500 - $1.750 \mathrm{~nm})$, correspondente ao infravermelho médio e composição colorida 3/4/5.

\section{Metodologia}

Preliminarmente, foram locadas as coordenadas geográficas (latitude e longitude) da carta topográfica 1: 50.000 , tanto para as aerofotos quanto para as imagens orbitais. Utilizou-se o método da quadrícula, onde a área de estudo foi dividida em células quadradas de $500 \mathrm{~m}^{2}$, levandose em consideração as respectivas escalas das aerofotos e imagens orbitais.

Posteriormente, fez-se uma interpretação preliminar nas aerofotos e imagens, estabelecendose a seguinte legenda:
$A=$ culturas anuais
$\mathbf{M}=$ mata ou capoeira
$\mathrm{C}=$ cana-de-açúcar
$\mathrm{U}=$ área urbana
$F=$ culturas perenes
I = área industrial
$P=$ pastagem
$\mathbf{R}=$ reflorestamento 


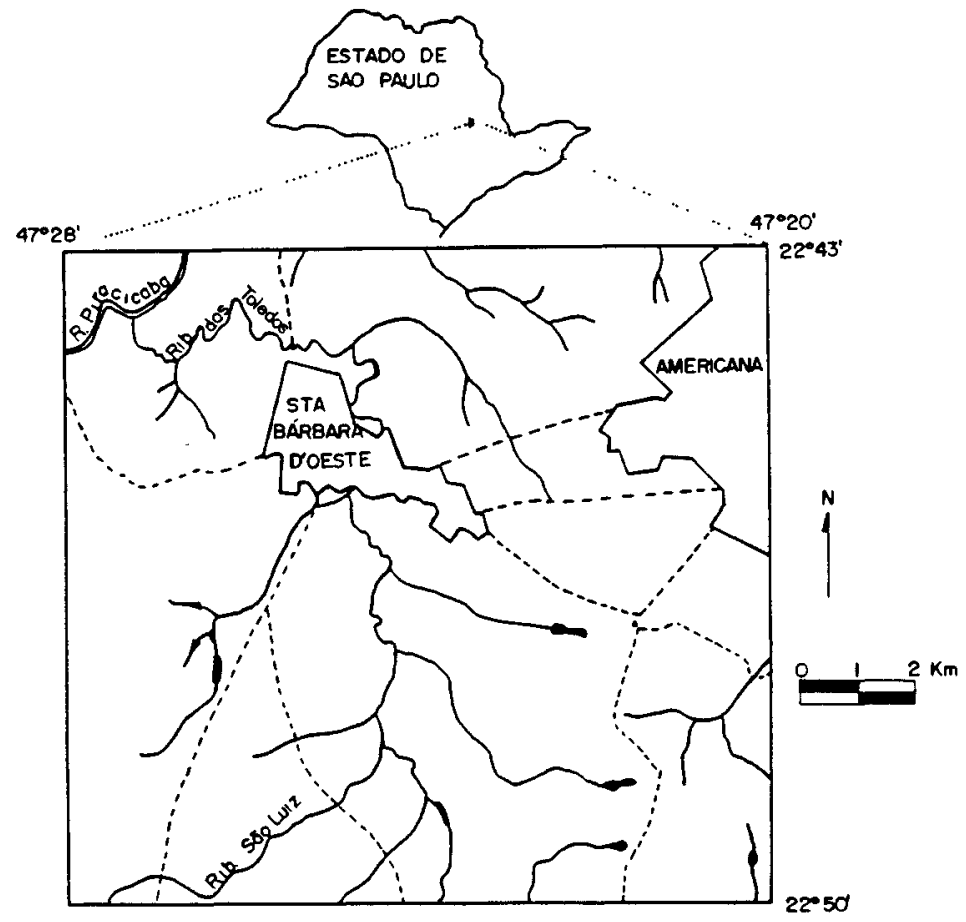

Figura 1 - Localização da área de estudo no Estado.

\begin{tabular}{|c|c|c|c|c|c|c|c|c|}
\hline $\begin{array}{l}\text { Elemento } \\
\text { s/Caracte- } \\
\text { rísticas }\end{array}$ & $\begin{array}{l}\text { Cultura } \\
\text { anual }\end{array}$ & $\begin{array}{l}\text { c ana } \\
\text { açúcar }\end{array}$ & $\begin{array}{l}\text { c u l t u ra } \\
\text { perene }\end{array}$ & mata & $\begin{array}{l}\text { reflores- } \\
\text { tamento }\end{array}$ & $\begin{array}{l}\text { p a s ta- } \\
\text { gem }\end{array}$ & $\begin{array}{l}a \dot{r} \text { e a } \\
\text { urbana }\end{array}$ & $\begin{array}{l}\text { área in- } \\
\text { dustrial }\end{array}$ \\
\hline Textura & fina & $\begin{array}{l}\text { fina ave- } \\
\text { ludada }\end{array}$ & granular & grosseira & fina & fina & grosseira & $\begin{array}{l}\text { grossei- } \\
\text { ra }\end{array}$ \\
\hline Porte & baixo & $\begin{array}{l}\text { r a s t e i ro } \\
\text { baixo médio }\end{array}$ & médio & alto & alto & rasteiro & - & - \\
\hline $\begin{array}{l}\text { Tonali- } \\
\text { dade }\end{array}$ & $\begin{array}{l}\text { cin z a } \\
\text { claro }\end{array}$ & $\begin{array}{l}\text { cinza muito } \\
\text { cl a ro a a } \\
\text { médio }\end{array}$ & cinza médio & cinza & cinza & $\begin{array}{l}\text { c in z a } \\
\text { claro a } \\
\text { médio }\end{array}$ & $\begin{array}{l}\text { c i n z a } \\
\text { médio }\end{array}$ & $\begin{array}{l}\operatorname{cin} \mathrm{z} \text { a } \\
\text { claro }\end{array}$ \\
\hline Telhado & - & uniforme & - & $\begin{array}{l}\text { não uni- } \\
\text { forme }\end{array}$ & uniforme & - & $\begin{array}{l}\text { não uni- } \\
\text { forme }\end{array}$ & $\begin{array}{l}\text { não uni- } \\
\text { forme }\end{array}$ \\
\hline $\begin{array}{l}\text { Aspectos } \\
\text { associa- } \\
\text { dos }\end{array}$ & $\begin{array}{l}\text { *curvas } \\
\text { de ní- } \\
\text { vel }\end{array}$ & $\begin{array}{l}\text { * carreado- } \\
\text { res e cur- } \\
\text { vas de ni- } \\
\text { vel }\end{array}$ & $\begin{array}{l}\text { *individuali- } \\
\text { zação das } \\
\text { plantas } \\
\text { *espaçamen- } \\
\text { tos largos } \\
\text { *configura- } \\
\text { ção geomé- } \\
\text { trica das } \\
\text { glebas }\end{array}$ & $\begin{array}{l}\text { *ausência } \\
\text { de carrea- } \\
\text { dores } \\
\text { *limites } \\
\text { irregula- } \\
\text { res }\end{array}$ & $\begin{array}{l}\text { * gl ebas } \\
\text { com limi- } \\
\text { tes regu- } \\
\text { lares } \\
\text { "carrea- } \\
\text { dores de- } \\
\text { finidos }\end{array}$ & $\begin{array}{l}\text { *árvores } \\
\text { isoladas } \\
\text { p a r a } \\
\text { sombrea- } \\
\text { mento }\end{array}$ & $\begin{array}{l}\text { *quartei- } \\
\text { r o e s, } \\
\text { r u a s, } \\
\text { prédios, } \\
\text { cas as, } \\
\text { aspectos } \\
\text { geomé- } \\
\text { tricos }\end{array}$ & $\begin{array}{l}\text { *galpão } \\
\text { localiza- } \\
\text { çāo pró- } \\
\text { xima a } \\
\text { grandes } \\
\text { culturas }\end{array}$ \\
\hline
\end{tabular}

Figura 2 - Quadro de chave de interpretação obtida das fotografias aéreas, escala 1:35.000. 
TABELA 1 - Chave de interpretação dos elementos analisados, obtida de imagens orbitais TM/LANDSAT-5, escala 1:100.000.

\begin{tabular}{|c|c|c|c|c|c|c|}
\hline $\begin{array}{l}\text { Elementos/Ca- } \\
\text { racterísticas }\end{array}$ & $\begin{array}{l}\text { c a n a d e } \\
\text { açúcar }\end{array}$ & mata & $\begin{array}{l}\text { refloresta- } \\
\text { mento }\end{array}$ & pastagem & área urbana & $\begin{array}{l}\text { área in- } \\
\text { dustrial }\end{array}$ \\
\hline Textura & fina & grosseira & fina & fina & grosseira & grosseira \\
\hline $\begin{array}{l}\text { Tonalidade } \\
\text { (banda 3) }\end{array}$ & $\begin{array}{l}\text { cinza claro } \\
\text { médio }\end{array}$ & cinza escuro & $\begin{array}{l}\text { cinza médio } \\
\text { a escuro }\end{array}$ & $\begin{array}{l}\operatorname{cin~} \mathrm{za} \\
\text { claro }\end{array}$ & cinza claro & cinza claro \\
\hline $\begin{array}{l}\text { Tonalidade } \\
\text { (composição } \\
\text { c o lorida } \\
3 / 4 / 5 \text { ) }\end{array}$ & $\begin{array}{l}* \text { diversos } \\
\text { tons de verde } \\
* \text { azul arro- } \\
\text { xeado }\end{array}$ & $\begin{array}{l}v \text { e } r d e \\
\text { escuro }\end{array}$ & $\begin{array}{l}v \text { e } r \text { d e } \\
\text { escuro }\end{array}$ & amarelado & $\begin{array}{l}\text { * róseo } \\
\text { *arroxeado }\end{array}$ & $\begin{array}{l}\text { róseo } \\
\text { arroxeado }\end{array}$ \\
\hline $\begin{array}{l}\text { Aspectos } \\
\text { associados }\end{array}$ & $\begin{array}{l}\text { *carreadores } \\
\text { * conforma- } \\
\text { ções geomé- } \\
\text { tricas dos } \\
\text { talhões }\end{array}$ & $\begin{array}{l}* \quad \text { limites } \\
\text { irregulares }\end{array}$ & $\begin{array}{l}* \text { limites } \\
\text { geométricos }\end{array}$ & - & $\begin{array}{l}* \quad \text { ruas, } \\
\text { aspectos } \\
\text { geométri- } \\
\text { cos }\end{array}$ & $\begin{array}{l}\text { * galpões } \\
\text { localizados } \\
\text { próximos a } \\
\text { g r a n d e s } \\
\text { culturas }\end{array}$ \\
\hline
\end{tabular}

Os parâmetros fotográficos mais importantes observados na interpretação da vegetação e áreas agrícolas nas imagens foram: tonalidade, textura, padrão, forma, dimensão, sombra, cor, topografia e aspectos relacionados (SANTOS et al., 1980).

Estabeleceu-se assim, uma chave de interpretação (KOFFLER et al., 1979 e KOFFLER, 1982), considerando-se os padrões característicos da imagem fotográfica (utilizando-se estereoscópio de espelhos) e orbital (utilizando lupa). Tais chaves estão resumidas nao Figura 2 e TABELA 1. A grade de pontos foi feita sobre "overlay", e fixada nas aerofotos e imagens orbitais para a interpretação propriamente dita, classificando-se cada quadrícula, segundo a categoria predominante. Portanto, o mapa final é constituído por uma quadrícula, cujas células receberam um símbolo segundo a legenda, previamente estabelecida, na escala 1: 100.000 .

Pela contagem das células referentes à cada categoria, têm-se a área para cada tipo de uso, podendo-se estabelecer a porcentagem de ocupação.

\section{RESULTADOS E DISCUSSĀO}

Comparando-seos mapas de uso do solo (Figuras 3 e 4), observa-se que pelas fotogra- fias aéreas foi possível identificar áreas de culturas anuais e perenes, o que não ocorreu com a utilização de imagens orbitais, devido ao nível de detalhamento proporcionado pelas aerofotos.

Nota-se que a área cultivada com cana-de-açúcar, praticamente permaneceu constante nos dois períodos analisados, $66,8 \%$ (1978) e $66 \%$ (1991), sendo bem mais alto que os $34,22 \%$ encontrados na região de Jaú por KOFFLER et al. (1980).

Com relação à vegetação, observase uma diminuição da área de mata, de $0,8 \%$ pelas fotos aéreas, para $0,4 \%$ das imagens orbitais. Para o reflorestamento, constata-se o contrário, isto é, $4,7 \%$ em 1978 para 5,2\% em 1991. O ocorrido seria devido a área de ocorrência de mata e de reflorestamento serem relativamente pequenas, $e$ com o agravante da escala da imagem orbital ser menor, $a$ interpretação desses dois elementos (mata e reflorestamento) confundiam-se.

Outro aspecto pode ter sido devido à análise temporal entre 1978 e 1991 , onde se observa uma diminuição da vegetação natural para um aumento (substituição) da floresta implantada.

A área de pastagem teve um decréscimo, repectivamente de $10,2 \%$ para $5,5 \%$, de 1978 a 91 . Isto se deve ao aumento da área urbana de $14,5 \%$ para $22,3 \%$. 

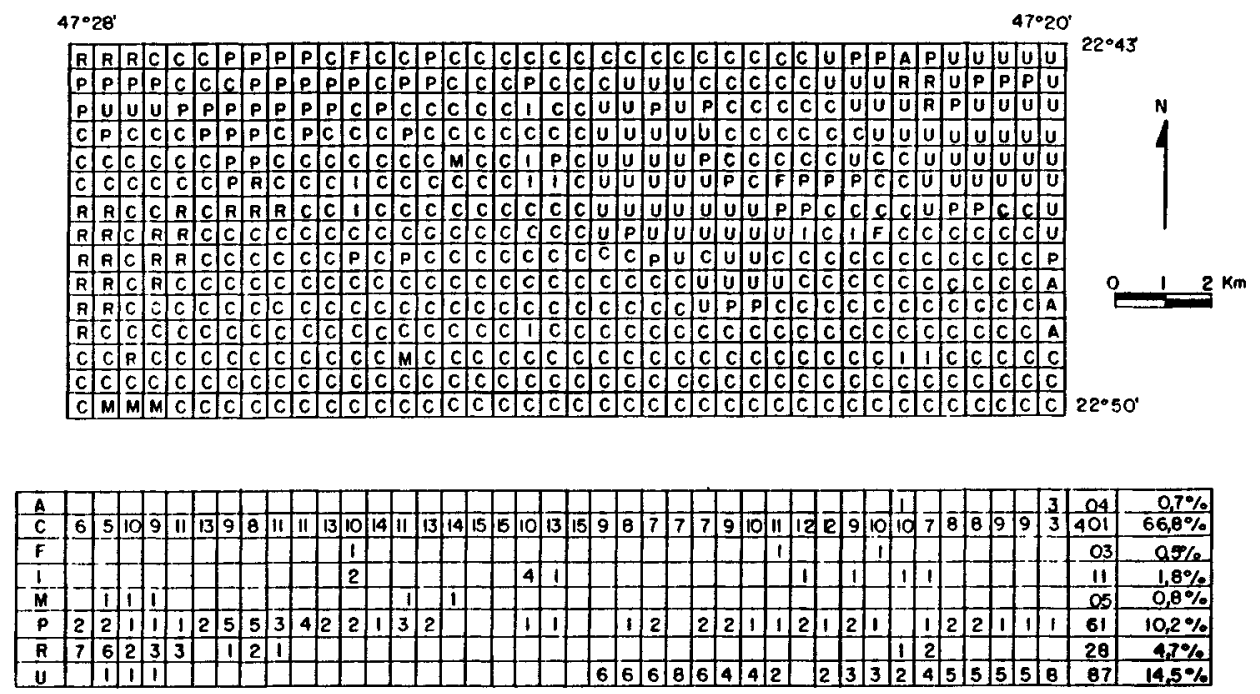

LE GEN D A

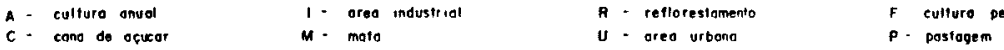
1. area industrial
R. reflorestimmento
F culturo perene

Figura 3 - Mapa de controle da interpretação e do uso do solo da região de Santa Bárbara D Oeste. Extraído de fotografias aéreas convencionais, na escala aproximada de 1:35.000, do vôo de recobrimento de 25/6/1978.

$47^{\circ} 28^{\prime}$

$47^{\circ} 20^{\circ}$

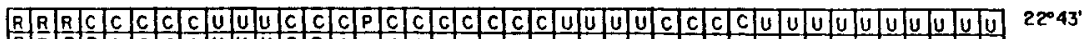

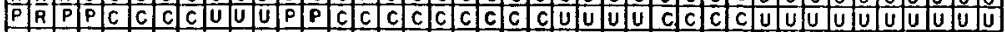

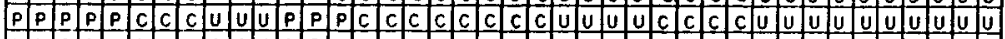

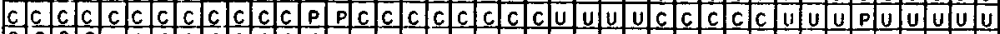

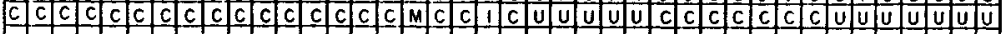

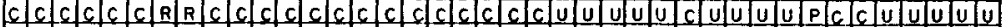

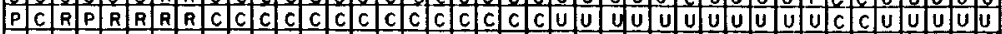

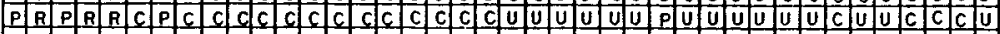

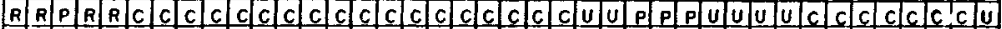

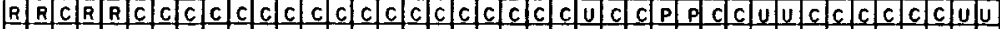

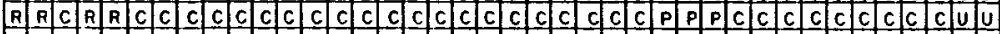

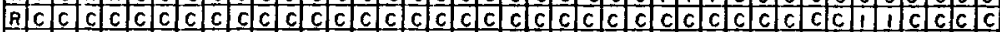

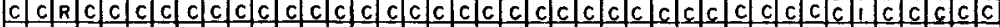

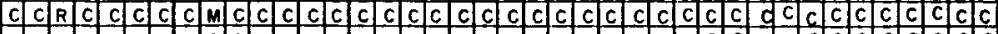

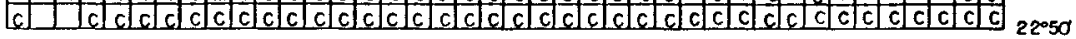

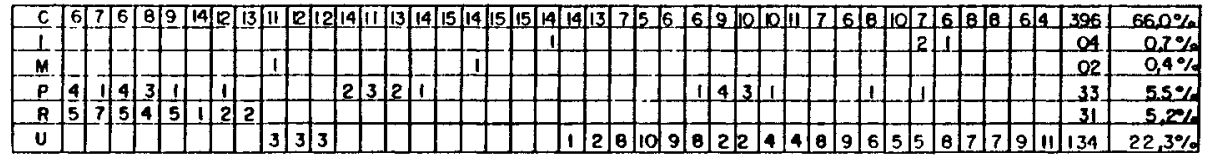

$$
\begin{aligned}
& \text { LE GENDA }
\end{aligned}
$$

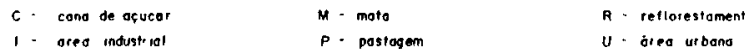

Figura 4. Mapa de controle da interpretação e do uso do solo da região de Santa Bárbara D’Oeste. Extraído de imagens TM/LANDSAT-5, bandas 3,4 e 5 e composição colorida 3/4/5, na escala 1:100.000, de $12 / 9 / 1991$.

Portanto, com relação a utilização dos dois produtos fotográficos, nota-se que as fotografias aéreas proporcionaram um maior detalhamento na identificação dos padrões de uso da terra quando comparadas com as imagens orbitais, sendo que para estas, na área de estudo, a banda 3 e a composição colorida se mostraram mais apropriadas, concordando parcialmente com SARAIVA et al. (1987), que concluíram serem as bandas 3,4 e 5 as mais eficientes. 
A identificação de culturas que apresentam características espectrais próprias, como a cana-deaçúcar, $\boldsymbol{\epsilon}$ facilitada em qualquer que seja o produto de sensoriamento remoto, concordando com KOFFLER (1982).

Pelos mapas de uso da terra (Figuras 3 e 4), nota-se que a utilização do solo da área de estudo está de acordo com o apresentado por CHIARINI; DONZELI (1973) e pelo mapeamento de Aptidão das Terras elaborado pelo MINISTÉRIO DA AGRICULTURA (1979), isto E, a região de Santa Bárbara D'Oste tem sua capacidade de uso enquadrada, em sua grande maioria, na classe IV terras mais apropriadas para pastagens.

Podem porém, serem utilizadas à exploração de plantas perenes, que proporcionem proteção ao solo. A utilização da cana-de-açúcar, cujas áreas estão sujeitas a problemas sérios de erosão, devido ao uso intensivo, também pode ser cultivada. Nesse caso, entretanto, deve-se aplicar práticas intensivas de conservação e com aptidão baseada em práticas agrícolas que refletem um alto nível tecnológico.

É importante deixar claro que, as diferentes escalas e Épocas dos produtos fotográficos, podem prejudicar ligeiramente 0 nível de detalhamento obtido.

\section{CONCLUSÕES}

As fotografias aéreas (1:35.000) proporcionaram um maior nível de detalhamento na identificação do uso da terra. Entre as imagens orbitais, a banda 3 e a composição colorida 3/4/5 (escala 1: 100.000 ) do TM/LANDSAT-5, foram as que melhor se apresentaram para o mapeamento do uso da terra. Durante o período de 1978 a 1991, na região de Santa Bárbara D'Oeste, a área de ocorrência da cana-de-açúcarpermaneceu a mesma, as áreas de mata e pastagem diminuíram, enquanto que as áreas de reflorestamento e urbana aumentaram.

As diferentes características das imagens fotográficas possibilitaram caracterizar as ocorrências e distribuições das diversas comunidades de uso do solo na região.

\section{REFERENCIAS BIBLIOGRÁFICAS}

CHIARINI, J.V.; DONZELI, P.L. Levantamento por fotointerpretaçăo das classes de capacidade de uso das terras do estado de Sao Paulo. Campinas: IAC, 1973, 20P. (Instituto Agronômico. Boletim técnico 3).
COMISSĀO DE SOLOS. Levantamento de reconhecimento dos solos do Estado de São Paulo. Rio de Janeiro, 1960. (Serviço Nacional de Pesquisa Agronómica. Boletim 12).

INSTITUTODE PESQUISAS TECNOLÓGICAS. Mapa geológico do Estado de São Paulo, São Paulo, 1981, 126p. (IPT. Série monografias 6, Publicação IPT, 1184).

KOFFLER, N.F. Identificação da cultura da cana-deaçúcar (Saccharum spp) atraves de fotografias aéreas infravermelhas coloridas e dados multiespectrais do satélite LANDSAT. Piracicaba, 1982. 234p. (Tese de Doutorado) - Escola Superior de Agricultura "Luiz de Queiroz"/USP.

KOFFLER, N.F.; CAVALI, A.C.; CHIARINI, J.V.; NOGUEIRA, F.P. Inventário canavieiro com o auxílio de fotografias aéreas. Piracicaba: PLANALSUCAR, 1979. 38p.

KOFFLER, N.F.; CAVALI, A.C.; CHIARINI, J.V.: NOGUEIRA, F.P. Inventário canavieiro com o auxilio de fotografias aéreas - a grande região de Jaú no ano safra $1979 / 80$. BOLETIM TECNICO PLANAlsuCaR, Piracicaba, v.2, n.4, p.1-22. 1980.

KOFFLER, N.F.; FRANÇA, G.V.; CAMPOS, H.; LAVORENTI, N.A. Identificação da cultura de canade-açúcar através de fotografias aéreas e dados do satélite LANDSAT. BOLETIM TECNICO PLANALSUCAR, Piracicaba, 1983, 68p.

MINISTERIO DA AGRICULTURA. Aptidão agricola das terras do Estado de São Paulo (estudos básicos para planejamento agrícola; aptidăo agrícola das terras). Brasilia: BINAGRI, 1979. 114p. (Estudos Básicos e Planejamento Agrícola. Aptidāo Agrícola das Terras, 20).

OLIVEIRA, J.B.; MENK, J.R.F.; ROTTA, C.L. Levantamento pedológico semidetalhado dos solos do Estado de São Paulo: quadrícula de Campinas. Campinas: Instituo Agronômico, 1977.

ROSA, R.A. Utilização de imagens TM/LANDSAT em levantamento de uso do solo. In: VI SIMPÓsio BRASILEIRO DE SENSORIAMENTO REMOTO, 6., Manaus, 1990, Annis... São José dos Campos, INPE, 1990. v.2, p.419-425.

SANTOS, A.P.; NIERO, M.; LOMBARDO, M.A. Interpretaçáo de dados de sensoriamento remoto no uso da terra. In: Introduçăo as técnicas de sensoriamento remoto e aplicacăio: curso de treinamento. São José dos Campos: Instituto Nacional de Pesquisas Espaciais, 1980. 318p. 
SĀO PAULO. Atlas do zonamento agrícola do Estado de São Paulo (Comissão). São Paulo: IAC/CPA/SA, 1974. v.1.

SARAIVA, I.R.; TRINDADE, M.L.P.; HERNANDEZ FILHO, P. Avaliação visual das imagens do sensor "Thematic Mapper" na classificação da vegetação. Boletim técnico IF., São Paulo, v.41, n.2, p.323-326. 1987.
STEINER, D. Time dimension for crop surveys from space. Photogrammetric Enginnering. Falls Church, v.36, n.2, p.187-194. 1970.

Enviado para publicação em 10.03 .93 Aceito para publicação em 10.09 .93 